\title{
Commentary: More valuable data on aortic blood flow patterns in valve-sparing aortic root replacements
}

Tohru Asai, MD, PhD

\author{
From the Department of Cardiovascular Surgery, Juntendo University, Tokyo, Japan. \\ Disclosures: Author has nothing to disclose with regard to commercial support. \\ Received for publication March 16, 2019; accepted for publication March 18, 2019; available ahead of print April \\ 24, 2019. \\ Address for reprints: Tohru Asai, MD, PhD, Department of Cardiovascular Surgery, Juntendo University, Faculty \\ of Medicine 2-1-1, Hongo, Bunkyo-ku, Tokyo 113-8421, Japan (E-mail: t.asai.jj@juntendo.ac.jp). \\ J Thorac Cardiovasc Surg 2020;159:811-2 \\ $0022-5223 / \$ 36.00$ \\ Copyright (C) 2019 by The American Association for Thoracic Surgery \\ https://doi.org/10.1016/j.jtcvs.2019.03.079
}

In this issue of The Journal of Thoracic and Cardiovascular Surgery, Oechtering and colleagues ${ }^{1}$ presented findings on blood flow pattern changes observed by 4-dimensional flow magnetic resonance imaging (MRI) in the thoracic aorta distal to the aortic root prosthesis in valve-sparing aortic root replacement (VSARR). Oechtering and colleagues ${ }^{1}$ recruited 18 patients undergoing VSARR (with 6 tube grafts and 12 physiologically shaped sinus prosthesis grafts) and 18 healthy volunteers (12 age-matched and 6 young) as a control group. By means of a sophisticated analysis method, Oechtering and colleagues ${ }^{1}$ specifically focused on the blood flow pattern and the wall shear stress in the remaining distal aorta. They concluded that the study revealed disturbed flow patterns distal to the aortic root prosthesis in most patients undergoing VSARR, even when a sinus-shaped prosthesis was used. The distal thoracic aorta geometry was interestingly classified into 3 shapes, round, cubic, and gothic. Although not quantified, "kinking" was defined as an abrupt angular deviation from the anatomically given course of the aorta. This kinking seems to be related to flow pattern changes, potentially increasing wall shear stress.

Four-dimensional flow MRI offers high potential in measuring and characterizing blood stream patterns, and it has recently been increasingly reported in the cardiovascular literature, particularly in relation to aortic surgery. ${ }^{2}$ Altered blood flow patterns have been found to increase wall shear stress, which potentially promotes vessel wall change, aortic remodeling, atherosclerotic plaque induction, and aneurysm development. It also potentially increases the left ventricular workload. Reading the precisely and beautifully presented data and figures of Oechtering and colleagues ${ }^{1}$ is like opening a door to new vistas in aortic surgery.

Thoracic aortic surgery has historically been not only technically demanding, but a procedure with high

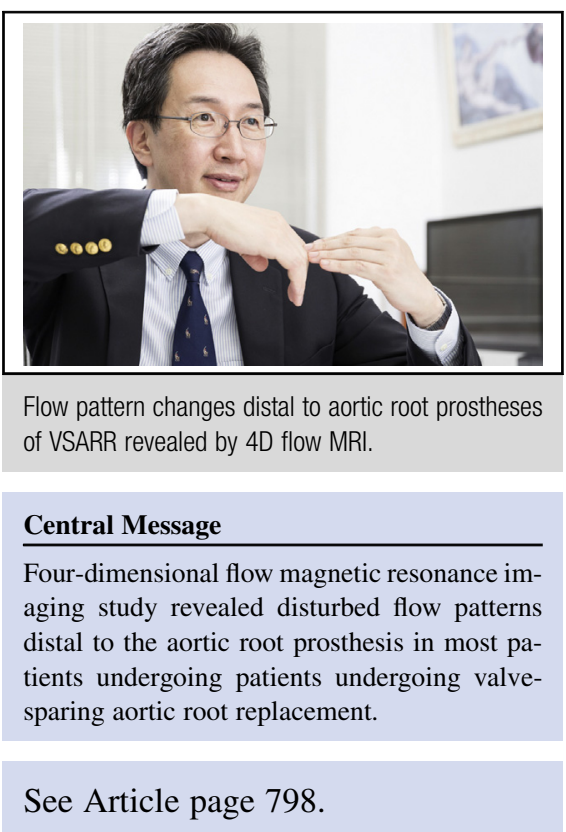

mortality. Artificial grafts were porous, requiring preclotting, and perfect control of bleeding has been the key to success the aortic surgery for many years. Many surgeons had a tendency to make a graft slightly longer for ease of checking anastomotic hemostasis or putting in additional sutures. In my surgical observation, the morphology of thoracic aortic aneurysms exhibits not only luminal "dilatation" but also "elongation" of the vessel. ${ }^{3}$ If the native aorta is already elongated, or the graft is longer than the aorta, the extra length may conceivably result in distortion or kinking. The description by Oechtering and colleagues ${ }^{1}$ of postoperative aortic shapes suggests that we may need to modify our current surgical approach, not only focusing on the reconstruction of the valve-sparing root portion but also taking into consideration the possibility of shortening the remaining aorta to streamline the aortic shape.

We are probably about to open a new era in aortic surgery. With better understanding of flow analysis with this sophisticated 4-dimensional flow MRI analysis, aortic reconstruction may be optimized, with new surgical design and novel prosthesis development. Although the clinical relevance of each finding is not clear at this point, more patient numbers with cautious long-term follow-up and more investigation are warranted. 


\section{References}

1. Oechtering TH, Sieren M, Hunold P, Hennemuth A, Huellebrand M, Scharfschwerdt M, et al. Time-resolved 3-dimensional magnetic resonance phase contrast imaging (4D Flow MRI) reveals altered blood flow patterns in the ascending aorta of patients with valve-sparing aortic root replacement. $J$ Thorac Cardiovasc Surg. 2020;159:798-810.e1.
2. Gaudino M, Piatti F, Lau C, Sturla F, Weinsaft JW, Weltert L, et al. Aortic flow after valve sparing root replacement with or without neosinuses reconstruction. J Thorac Cardiovasc Surg. 2019;157:455-65.

3. Asai T, Suzuki T, Kinoshita T. The proximalization of the arch anastomosis. J Vis Surg. 2018;4:83. 